\title{
Cross-Sectional Inquiry on Employability and Employment Status of Bachelor of Secondary Education Graduates (2016-2018): A Tracer Study
}

Manuel E. Caingcoy ${ }^{*}$, Desiree A. Barroso

${ }^{\mathrm{T}}$ Assistant Professor, Bukidnon State University, Malaybalay City, 8700, Philippines

${ }^{2}$ Associate Professor, Bukidnon State University, Malaybalay City, 8700, Philippines

\author{
Article History \\ Received: 12.10 .2020 \\ Accepted: 27.10 .2020 \\ Published: 30.10 .2020 \\ Journal homepage:
}

https://www.easpublisher.com/easmb

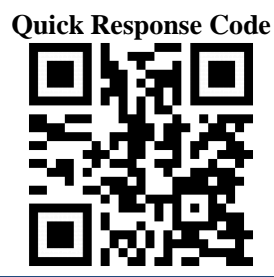

Abstract: Higher education institutions are expected to produce quality and competitive graduates for the job market and nation-building. In realizing this role, the Bukidnon State University needs to ensure that graduates may land a job-relevant and aligned with their education and training. With this, a tracer study was conducted to verify whether the three batches of graduates are employed and are employable. It ascertained their employability based on their work experience from graduation to the present job. It employed a cross-sectional method and data mining for the information of 326 graduates. The results revealed that the majority of graduates had jobs relevant to their education and training; yet, there was a significant difference in the employability of graduates across batches, except in terms of gender. Biological Science, Social Studies, and Math graduates were employable within the first six and twelve months compared to graduates from other curricula. It was claimed that the BukSU had prepared BSE graduates for employment. These results have implications for the strategic options in improving the programs. The study made some recommendations for future tracer initiatives. Keywords: Position, employment status, employability, gender, curricular program.

Copyright (C) 2020 The Author(s): This is an open-access article distributed under the terms of the Creative Commons Attribution 4.0 International License (CC BY-NC 4.0) which permits unrestricted use, distribution, and reproduction in any medium for non-commercial use provided the original author and source are credited.

\section{INTRODUCTION}

Higher education institutions are expected to produce quality and competitive graduates for the job market [1] and nation-building [2]. They are responsible for producing a quality workforce for the social, economic, and cultural development of the country. That is why HEIs prepare graduates to land jobs. One of the best ways HEIs can prepare them is to help them pass in the licensure examination by delivering quality instruction and by providing the relevant experience. Nonetheless, graduates' chances to land a teaching job are very slim or they may have a job that is not matched to their schooling and training. But if they can pass on the board examination, the more likely they can get a job relevant to their specialization, and the sooner a job can be obtained. In this way, they may contribute to the labor participation rate and employment rate of the country.

It may be a phenomenon that graduates have difficulty in the transition after graduation as they embark on employment. In the same month, they graduated, some might have got a job, while others opted to spend months in preparation for the licensure examination. There would be graduates who have a strong desire to work immediately after they finish college, yet they are constrained by the job conditions and requirements. One of these is a license. This requirement may prolong their waiting for a chance to land a teaching job. But if they can obtain a job a few months after graduation, that would be a factor for a greater chance and of their employability.

Employability has received a deep interest in colleges [3]. The term employability has been perceived differently. In one tracer study, it was understood as employed, unemployed, or never been employed [4]. To analyze closely, these concepts were taken interchangeably with the term employment status. They are the outcomes of whether graduates are employable or not. In the simplest terms, employability is the ability to get a job [5] but not the outcome of such ability. Aspiring Minds [3] delineated these two constructs. Employment status is an outcome of employability. In its report, employability status is at various degrees, such as did not get interview opportunities, got an interview opportunity, reached the final round, and employed. The higher one applicant can progress in this ladder, the more employable he or she is. Therefore, employment status can be taken as employed, unemployed, or underemployed. It is an outcome of employability, that is, the ability between the one who did not get an interview opportunity and the one who got the interview opportunity. This variance reflects two different employability levels.

In a study in which participants were undergraduates, employability was defined by students extrinsically in the early years of their studies with simplistic terms associated. This definition becomes 
intrinsically focused and sophisticated as they progressed in their studies. Extrinsically, students perceived employability based on what the employer thinks of the applicant [5]. This empirical evidence suggests that the perception of employability depends on one's maturity and as individuals mature, their idea of employability becomes focused on the self and not on how others perceive it.

Baking et al., [6] opined employability as the capability of individuals to move self-sufficiently within the labor market to realize the potential through sustainable employment. Smith et al., [7] identified six dimensions of employability (termed work-readiness): professional practice and standards, integration of theory and practice, lifelong learning, collaboration, informed decision-making, and commencementreadiness (confidence in starting a job in the discipline). This ideation is somewhat more complex than how employability was usually referred to in the past.

Employability and productivity are central issues in the strategic direction of higher education institutions $[6,3]$. The degree to which graduates can become productive in the industry or sector where they are in reflects the quality of the institution and its curriculum. This is the reason why these issues are of great concern to universities. Employability of graduates is a feedback to the university [3]. Whether it is from employers or students' perspective, it would always add value to decision-making and policy options.

In this research, employability is the distance between the day individuals have graduated and the day they get a job. This construct lacks empirical evidence and theoretical support. As a phenomenon, it is always dependent on internal and external conditions. The internal condition is inclusive of individual qualities, traits, skills, and capability, while the external condition may include job requirements, perception of employers, among others. This internal condition is similar to what Finch, Peacock and Levallet [8] identified in their study on the dynamic capabilities view of employability. These include intellectual, personality, meta-skill, and job-specific individual resources, which may become graduates' competitive advantage.

Employment status refers to whether or not graduates are employed, unemployed, or underemployed after they graduated from college. In a recent report, the Philippine Statistics Authority [9] described the employment status of Filipinos 15 years old and above: $93.7 \%$ are employed; $18.5 \%$ are underemployed, while $6.3 \%$ are unemployed. With optimistic statistics, it is of utmost interest that a higher percentage of BSE graduates are employed, and a few of them are underemployed or unemployed. These statistics are far more improved when the International Labor Organization [10] described the youth as pessimistic, demoralized, and in despair.
Infante et al., [11] have the same understanding of employment status as the current study, but they were limited to two categories, employed or not employed. Their findings revealed that graduates of the Guimaras State College were 69.9\% employed and $30.1 \%$ were not employed. However, it is not clear in their tracer study if those who are employed are really in the practice of their profession. Looking at the phenomenon of underemployment is also a very important undertaking.

The Bukidnon State University (BukSU), College of Education, traced its Bachelor of Secondary Education (BSE) graduates relevant to the preparation for quality assurance endeavors (i.e. AACCUP accreditation, Institutional Sustainability Assessment, ISO certification, and SUC leveling). These endeavors will look into the Licensure Examination Performance of BSE graduates, employment status, employability, and other relevant information. This study is also premised after the empirical evidence reported by Aspiring Minds [3] which revealed that both males and females are equally employable and have equal percentages of employment status, while males are slightly better when it comes to salary figures. Similarly, the present study intends to verify if there are variances in employment status and employability between genders and across disciplines such as biological science, Filipino, math, social studies.

This tracer study is instrumental in crafting strategic options for the university to prepare its future BSE graduates more competitively than what the university has already produced. By doing this, BukSU can have feedback on whether it has prepared graduates competitively or otherwise. This is indicated when graduates had landed jobs relevant to their profession and training, underemployed or unemployed. The results of this tracer study would provide vital information on opportunities, strengths, weaknesses, and threats that can be made bases on drawing lessons for more strategic options. This tracer study was intended to establish a profile on the employment status of BSE graduates and ascertain their employability when they were on the transition from college to career life. Employment status included the type of employer and position. Employability was clustered into three: employable to non-permanent positions, highly employable to permanent positions, and employable to permanent positions. It determined whether gender, year graduated, and curricular programs can yield variance in BSE graduates' employability. In the end, this study identified strategic options for improving BSE programs and in designing program enhancement that maximizes graduates' competitive edge.

\section{METHODOLOGY}

The study used a cross-sectional research method to compare the employability and employment status of 2018, 2017, and 2016 BSE graduates (see Table-1). It data mined secondary data from the 
Chairperson's office, which were gathered by the commissioned faculty to tract graduates of every batch a few months after graduation. The tracer was done online using email addresses, social media, and google forms. The commissioned faculty sent invitation to graduates and a copy of the survey tool that required personal and professional information relevant to employment and employability. These data included their position/rank, salaries, employers, year graduated, and the month/year they were first employed or the subsequent employment. For profiling purposes, these data were analyzed using frequency and percentages to describe the employability and employment status of these graduates. Employability was categorized into the following: (1) employable to non-permanent positions (within 1 to 6 mos.), (2) highly employable to permanent positions (within 7 to 12 mos.), and (3) employable to permanent positions (13 mos. and above). For cross-sectional analysis, the secondary data were processed and analyzed using a t-test for independent samples and analysis of variance. Since the data were already available at the office of the BSE chairperson, the study did not recruit graduates as participants. And so, there was no need for the proponents to secure informed consent form from them. Instead, it asked permission from the appropriate authorities to use the existing data for this research. The study did not have any related risks. The names of the graduates are not revealed in the manuscript.

\section{RESULTS AND DISCUSSION}

Table-1 illustrates the number of graduates involved in the tracer study. As reflected below, it covered three batches. In the 2016 tracer, it included the BPE-SPE program, while it was not included in the 2017 and 2018 tracking, respectively. As noticed, females outnumbered males across three batches. In 2018, many of them came from the Social Studies program. For the 2017 batch, English, Filipino, and Math are almost equally represented. For 2016, English and Social Studies have greater representations than other curricular programs. In 2016, there were 136 graduates from all curricular programs, and the tracer included 117. This means that the tracing involved $86.02 \%$ of this batch. For the batch 2017, there were 156 graduates and it traced 104 which is $66.66 \%$ of the batch's members. For the 2018 batch, the College of Education had produced 224 graduates and 104 of them or $46.42 \%$ were involved. Largely, more than $70 \%$ of the 2018 traced graduates were employable to nonpermanent positions/jobs within the first six months after graduation. This is so since at this time they do not have a license yet, which is the requirement in the practice of their profession and employment in public schools. This means that most of the 2018 graduates had jobs a few months after graduation. It is assumed that they did this to gain experience, which is needed for applying a permanent teaching position at the Department of Education. Most of the time, graduates during these months are preparing for the September licensure examination. This is a regular schedule for graduates of Teacher Education programs. This resulted in very few (4.80) who were highly employable to permanent positions within 7 to 12 months. More than $10 \%$ did not indicate the date they were employed.

Table-1: Percentage and Frequency Distribution of Traced BSE Graduates

\begin{tabular}{|c|c|c|c|c|c|}
\hline Batch & Gender & $\mathbf{f}(\%)$ & Curricular Programs & Representatives (f/\%) & Sample \\
\hline 2018 & $\begin{array}{l}\mathrm{M} \\
\mathrm{F}\end{array}$ & $\begin{array}{l}29(27.88) \\
75(72.11)\end{array}$ & $\begin{array}{l}\text { BSE-BioSci } \\
\text { BSE-English } \\
\text { BSE-Filipino } \\
\text { BSE-Math } \\
\text { BSE-SocStud }\end{array}$ & $\begin{array}{l}12(11.53) \\
20(19.23) \\
24(23.07) \\
8(7.69) \\
40(38.46)\end{array}$ & 104 \\
\hline 2017 & $\begin{array}{l}\mathrm{M} \\
\mathrm{F}\end{array}$ & $\begin{array}{l}24(23.07) \\
81(77.14)\end{array}$ & $\begin{array}{l}\text { BSE-BioSci } \\
\text { BSE-English } \\
\text { BSE-Filipino } \\
\text { BSE-Math } \\
\text { BSE-SocStud }\end{array}$ & $\begin{array}{l}14(13.33) \\
25(23.80) \\
25(23.80) \\
24(22.85) \\
17(16.19) \\
\end{array}$ & 105 \\
\hline 2016 & $\begin{array}{l}\mathrm{M} \\
\mathrm{F}\end{array}$ & $\begin{array}{l}31(26.49) \\
86(73.50)\end{array}$ & $\begin{array}{l}\text { BSE-BioSci } \\
\text { BSE-English } \\
\text { BSE-Filipino } \\
\text { BSE-Math } \\
\text { BSE-SocStud } \\
\text { BPEd }\end{array}$ & $\begin{array}{l}12(10.03) \\
37(31.62) \\
11(9.40) \\
14(11.06) \\
34(29.05) \\
9(7.69)\end{array}$ & 117 \\
\hline
\end{tabular}


Table-2: Clustered Employability Profile of 2018, 2017, and 2016 BSE Graduates

\begin{tabular}{|l|l|l|l|l|}
\hline Batch & Clusters & f & $\mathbf{\%}$ & Qualitative Description \\
\hline \multirow{4}{*}{2018} & Within 1-6 mos. & 73 & 70.19 & Employable to non-permanent positions \\
\cline { 2 - 5 } & Within 7-12 mos. & 5 & 4.80 & Highly employable to permanent positions \\
\cline { 2 - 5 } & Within 13 mos. or so & 15 & 14.42 & Employable to permanent positions \\
\cline { 2 - 5 } & Not indicated & 11 & 10.57 & - \\
\hline \multirow{3}{*}{2017} & Within 1-6 mos. & 41 & 39.04 & Employable to non-permanent positions \\
\cline { 2 - 5 } & Within 7-12 mos. & 21 & 20.00 & Highly employable to permanent positions \\
\cline { 2 - 5 } & Within 13 mos. or so & 27 & 25.71 & Employable to permanent positions \\
\cline { 2 - 5 } & Not indicated & 16 & 15.23 & - \\
\hline \multirow{3}{*}{2016} & Within 1-6 mos. & 38 & 32.49 & Employable to non-permanent position \\
\cline { 2 - 5 } & Within 7-12 mos. & 5 & 4.27 & Highly employable to permanent positions \\
\cline { 2 - 5 } & Within 13 mos. or so & 64 & 54.70 & Employable to permanent positions \\
\cline { 2 - 5 } & Not indicated & 10 & 8.54 & - \\
\hline
\end{tabular}

The employability of the 2017 BSE traced graduates is also shown in Table-2. Close to $40 \%$ were employable to non-permanent positions. This is far behind compared to the 2018 batch. Moreover, 20\% of this batch was highly employable to permanent positions. These statistics are four times greater than those in the 2018 Batch. Approaching to $26 \%$ were employable to permanent positions within 7 to 12 months. Again, this is greater than those from 2018 graduates.

For the 2016 batch, almost $32 \%$ were employable to non-permanent positions. Note that the statistics of those who were highly employable to permanent positions were almost the same as those in the 2018 batch. Lastly, close to $50 \%$ of this batch was clustered as employable to permanent positions. Comparing this with the 2018 and 2017 graduates, there were more graduates from batch 2016 who had landed permanent jobs a year or so after they had graduated from college. But this does not mean that the 2016 graduates are more employable than the other batches. This simply means that the 2018 graduates preferred to settle a job a few months after graduation, even if these jobs are non-permanent and there is no job security. Many from this batch prefer to have experience before taking the board examination. Woya [12] unveiled that
$82.3 \%$ of their statistics graduates were employed, while $17.75 \%$ suffered from unemployment. This study revealed further that there is a percentage of graduates who were yet employed and never been employed. Among IT people, $71.88 \%$ of the graduates were employed [13].

Table-3 presents more specific information on which curricular programs are more employable within the first six months and the second six months or so. For the 2018 batch, $100 \%$ of the English group was employed within the first six months after graduation. More than $50 \%$ of the Social Studies and Filipino graduates were employed in the same period. For the batch 2017 , a great number $(79.16 \%)$ of the math graduates had been employed within the first six months. Many $(85.71 \%)$ of the BioSci graduates had been employed between 7 and 12 months after they graduated, and more than $40 \%$ of the Filipino majors were employed on the 13th month or later. As can be noticed in batch 2016, most of the BioSci graduates were employed in the first six months, while BPEd, English, and Filipino graduates were employed after a year they graduated. Across programs, a few had the jobs in the second six months after graduation. No one was employed from the BioSci, Filipino, and BPEd groups during this period.

Table 3: Employability Profile of 2018, 2017, and 2016 Graduates by Curricular Programs

\begin{tabular}{|c|c|c|c|c|c|c|c|}
\hline \multirow{2}{*}{\multicolumn{2}{|c|}{ Batch/Programs }} & \multicolumn{3}{|c|}{ Clustered Employability } & \multirow{3}{*}{$\begin{array}{c}\text { Missing } \\
1\end{array}$} & \multirow{3}{*}{$\begin{array}{c}\text { Actual } \\
11\end{array}$} & \multirow{3}{*}{$\begin{array}{r}\text { Total } \\
12\end{array}$} \\
\hline & & Within 1-6 mos. f (\%) & Within 7-12 mos. $\mathrm{f}(\%)$ & Within 13 mos. and above $f(\%)$ & & & \\
\hline \multirow[t]{5}{*}{2018} & BSE-BioSci & $6(50.00)$ & $5(41.66)$ & $0(0.00)$ & & & \\
\hline & BSE-English & $20(100.00)$ & $0(0.00)$ & $0(0.00)$ & 0 & 20 & 20 \\
\hline & BSE-Filipino & $16(66.66)$ & $0(0.00)$ & $7(29.16)$ & 1 & 23 & 24 \\
\hline & BSE-Math & $4(50.00)$ & $0(0.00)$ & $2(25.00$ & 2 & 6 & 8 \\
\hline & BSE-SocStud & $27(67.50)$ & $0(0.00)$ & $6(15.00)$ & 7 & 33 & 40 \\
\hline \multirow[t]{5}{*}{2017} & BSE-BioSci & $1(7.14)$ & $12(85.71)$ & $1(7.14)$ & 0 & 14 & 14 \\
\hline & BSE-English & $8(32.00)$ & $7(28.00)$ & $9(36.00)$ & 1 & 24 & 25 \\
\hline & BSE-Filipino & $8(32.00)$ & $0(0.00)$ & $11(44.00)$ & 6 & 19 & 25 \\
\hline & BSE-Math & $19(79.16)$ & $0(0.00)$ & $1(4.16)$ & 4 & 20 & 24 \\
\hline & BSE-SocStud & $5(29.41)$ & $2(11.76)$ & $5(29.41)$ & 5 & 12 & 17 \\
\hline \multirow[t]{6}{*}{2016} & BSE-BioSci & $8(66.33)$ & $0(0.00)$ & $4(33.33)$ & 0 & 12 & 12 \\
\hline & BSE-English & $9(24.32)$ & $4(10.81)$ & $23(62.16)$ & 1 & 36 & 37 \\
\hline & BSE-Filipino & $3(27.27)$ & $0(0.00)$ & $6(54.54)$ & 2 & 9 & 11 \\
\hline & BSE-Math & $2(14.28)$ & $0(0.00)$ & $9(64.28)$ & 3 & 11 & 14 \\
\hline & BSE-SocStud & $14(41.19)$ & $1(2.94)$ & $17(50.0)$ & 2 & 32 & 34 \\
\hline & BPed & $2(22.22)$ & $0(0.00)$ & $5(55.55)$ & 2 & 7 & 9 \\
\hline
\end{tabular}

Notes: 1-6 mos. Employable to non-permanent positions; 7-12 mos. Highly employable permanent positions; 13 mos. or above-less Employable to permanent positions 
A study found that Science majors are the most employable graduates, while Math majors can diversify their talents [14]. However, Baking et al., [6] rejected a null hypothesis stating a significant difference in employability across curricular programs. Therefore, all graduates from all degree programs are equally employable. Most of the BSE graduates $(53.6 \%)$ were employed within the first six months after graduation [15]. Domingo (2013) exposed that the majority of graduates were employed locally and a quarter waited for at least a month to six months before hired. In Abarro [16] it turned out that BSE Physical Education and Music majors had the highest employment of $86.67 \%$, while BSE General and Biological Science majors had the lowest employment of $61.84 \%$. As can be observed in Table-4, most (89.4\%) of the 2018 BSE graduates had jobs relevant to their education and training since most of them had mostly experienced teaching in private schools. Less than ten percent $(9.6 \%)$ had a job not relevant to their education and training. However, it can be noticed that most (88.5\%) of them had a temporary status of employment. Only very few $(9.6 \%)$ had permanent employment. As argued above, this was because they were still about to take the licensure examination within the first six months after graduation. For the 2017 graduates, many (81.9\%) of them also had the relevant work experience, teaching in private schools, while more than ten percent $(11.4 \%)$ had work experience not relevant to their education and training. Noticeably, there are close statistics between those who had permanent $(40 \%)$ and non-permanent (53.3\%) employment. After three years (2016-2019), the 2016 graduates have almost similar statistics to those who graduated in 2018 when it comes to graduates who had employment relevant and not relevant to their education and training. Currently, most $(60.7 \%)$ of the 2016 graduates have permanent jobs. This means that many of them have landed jobs in the Department of Education or State Colleges and Universities. Generally, the percentage of those who landed a permanent job increased as graduates had more years after graduation. This is so since they have acquired more years of experience.

A study found that majority of graduates had landed jobs aligned with pre-service preparations [6]. Further, Napallaton et al., [17] found that most graduates had regular employment status. A great of the BEEd graduates were found employed in the field of teaching. Also, Aquino et al., [18] traced that majority of Teacher Education graduates had employment relevant to their degrees. Moreover, Woya [12] presented that $65.8 \%$ of the employed graduates had permanent work, while a portion (16.5\%) had temporary jobs. In Abarro [16], both the BSE and BEE graduates were found employable, in particular, $74.24 \%$ were employed, $11.86 \%$ were underemployed, a few of them were $(8.81 \%)$ were self-employed, and a small portion $(5.09 \%)$ were unemployed. Likewise, it was showed that $72.1 \%$ of their Science and Mathematics graduates had full and permanent employment, while $18.9 \%$ had full and non-permanent. Only a portion $(2.3 \%)$ was in part-time jobs. It was also indicated that $83.7 \%$ had teaching-related jobs, while the other portion $(9.3 \%)$ had non-teaching jobs [19].

Table-4: Distribution of Position and Employment Status of 2018, 2017, and 2016 BSE Graduates

\begin{tabular}{|c|c|c|c|c|c|c|}
\hline Batch & Position & f & \% & Employment Status & f & \% \\
\hline \multirow{3}{*}{2018} & Teacher & 93 & 89.42 & Permanent & 10 & 9.61 \\
\cline { 2 - 7 } & Not a Teacher & 10 & 9.61 & Non-Permanent & 92 & 88.46 \\
\cline { 2 - 7 } & Not indicated & 1 & 1.00 & Not indicated & 2 & 1.92 \\
\hline \multirow{3}{*}{2017} & Teacher & 86 & 81.90 & Permanent & 42 & 40.00 \\
\cline { 2 - 7 } & Not a Teacher & 12 & 11.42 & Non-Permanent & 56 & 53.33 \\
\cline { 2 - 7 } & Not indicated & 7 & 6.66 & Not indicated & 7 & 6.66 \\
\hline 2016 & Teacher & 105 & 89.74 & Permanent & 71 & 60.68 \\
\cline { 2 - 7 } & Not a Teacher & 11 & 9.40 & Non-Permanent & 45 & 38.46 \\
\cline { 2 - 7 } & Not indicated & 1 & .85 & Not indicated & 1 & .85 \\
\hline
\end{tabular}

In Table-5, there are two types of employers of employed graduates regardless of whether the jobs are teaching or non-teaching-related. Very few of the 2018 graduates were employed in the public sector, while most of them were employed in the private sector. For the 2017 batch, there very close numbers between government and private employers. Lastly, most of the 2016 graduates were employed in government and some of them were in the private sector. These results suggest that as these graduates accumulate relevant work experiences, they would likely seek employment in government agencies, especially schools. As argued above, it took time for graduates to land permanent employment in government because the hiring and raking process requires teaching experience. This argument is based on testimonies among in-service teachers in the government.

Aquino et al., [18] traced that majority of Teacher Education graduates were employed in public schools. This was also true in another that reported that most of the BEEd graduates were employed by government agencies [17]. Besides, most (61.19\%) of the BSE and BEE graduates were employed in public schools, while a small number $(38.81 \%)$ was employed in private schools [16]. Those with teaching-related jobs, the majority $(53.5 \%)$ were employed in public secondary schools, some $(27.9 \%)$ private secondary schools, and a few $(2.3 \%)$ in private/public college or university [19]. 
Table-5: Distribution of Employers of 2018, 2017, and 2016 BSE Graduates

\begin{tabular}{|c|c|c|c|c|c|c|c|}
\hline \multirow{2}{*}{ Batch } & \multicolumn{2}{|c|}{ Government } & \multicolumn{2}{|c|}{ Private } & \multicolumn{2}{c|}{ Not Indicated } & \multirow{2}{*}{ Sample } \\
\cline { 2 - 7 } & $\mathrm{f}$ & $\%$ & $\mathrm{f}$ & $\%$ & $\mathrm{f}$ & $\%$ & \\
\hline 2018 & 22 & 21.15 & 82 & 78.84 & 0 & 0.00 & 104 \\
\hline 2017 & 52 & 49.52 & 49 & 46.66 & 4 & 3.80 & 105 \\
\hline 2016 & 69 & 58.97 & 47 & 40.17 & 1 & .85 & 117 \\
\hline
\end{tabular}

Tables 2 and 3 above set the parameters for comparing the three batches as to their employability. Table 6 below prepares further comparison of the batch groupings, curricular programs, and gender. Notice that the average months of employability among these batches explain further that the 2018 graduates preferred employment a few months (3.54 mos.) after graduation than the other two batches. They are the type of graduates who love to acquire experience even if they do not have a license to practice their profession. As evidenced in Table-5, most of them had landed private employment. Most of the 2017 graduates were employed within nine (9.36) months after graduation.
These graduates had landed jobs after they had taken the board examination. Therefore, between February and March in the following year, most of them were already hired. This is the time that schools started hiring teachers for the next school year. This is the batch prefers to apply for a job when they are highly employable already to permanent jobs. On the other hand, most of the 2016 graduates had landed jobs between 14 and 15 (14.52 mos.) months after graduation. This batch graduated in March 2016. Thus, they were hired between April and May 2017. The differences in the employability of these batches are further presented in Tables 7 and 8.

Table-6: Average Employability of BSE Graduates

\begin{tabular}{|c|c|c|c|c|c|}
\hline Batch & N & Mean & SD & SE & Employability \\
\hline 2018 & 94 & 3.54 & 4.74 & .48 & Employable to non-permanent jobs \\
\hline 2017 & 87 & 9.36 & 7.86 & .84 & Highly employable to permanent jobs \\
\hline 2016 & 101 & 14.52 & 10.50 & 1.04 & Employable to permanent jobs \\
\hline Total & 282 & 9.27 & 9.30 & .55 & Highly employable to permanent jobs \\
\hline
\end{tabular}

Table-7 presents the results of the analysis of variance, which compares the employability of three batches (2016-2018) of BSE graduates. F statistics (2) = $44.438, \mathrm{p}<.05)$ revealed significant differences in their employability. At this level, it is not clear which grouped vary significantly. When the 2016 and 2017 graduates are compared, the mean difference in employability is $5.15694 *$ ( 5 mos.). This difference is statistically significant at the 0.05 level. Thus, 2017 graduates are more employable to permanent jobs than their counterparts.

Comparing the 2016 and 2018 graduates, it turned out that the difference was more than 10 months.
This difference was also statistically significant. This suggests that the 2018 graduates can be employed earlier than the 2016 graduates. But again, the tendency is that these graduates are likely to land non-permanent jobs since they do not have a license yet within the first three months. However, there would be more 2016 graduates who would land in permanent jobs since they applied for jobs after a year or so. The 2017 and 2018 graduates were compared as to their employability. The mean difference shows a significant difference in their employability. This difference is almost six months. These results strengthened the claims made earlier.

Table-7: Analysis of Variance Comparing the Employability of the Three Batches of Graduates

\begin{tabular}{|c|c|c|c|c|c|}
\hline Groups & Sum of Squares & df & Mean Squares & F & Sig. \\
\hline Between Groups & 5783.227 & 2 & 2936.614 & 44.439 & .000 \\
\hline Within Groups & $18,346.748$ & 279 & 66.082 & & \\
\hline Total & $24,309.975$ & 281 & & & \\
\hline
\end{tabular}

Table-8: Post Hoc Test Results Comparing the Employability of BSE Graduates

\begin{tabular}{|c|l|c|c|c|}
\hline Compared Batches & & Mean Difference & SE & Sig. \\
\hline \multirow{2}{*}{2016 batch } & 2017 batch & $5.15694^{*}$ & 1.18905 & .000 \\
\cline { 2 - 5 } & 2018 batch & $10.98220^{*}$ & 1.16502 & .000 \\
\hline \multirow{2}{*}{2017 batch } & 2016 batch & $-5.15694^{*}$ & 1.18905 & .000 \\
\cline { 2 - 5 } & 2018 batch & $5.825268^{*}$ & 1.20936 & .000 \\
\hline \multirow{2}{*}{2018 batch } & 2016 batch & $-10.98220^{*}$ & .16502 & .000 \\
\cline { 2 - 5 } & 2017 batch & $-5.825268^{*}$ & 1.20936 & .000 \\
\hline
\end{tabular}

*The Mean Difference is significant at the 0.05 level 
Table-9 displays the results of comparing the employability of 2018, 2017, and 2016 BSE graduates using their gender. To take a closer look, there was no significant difference in the employability of male and female BSE graduates across the three batches. These results confirm the claim of the Aspiring Minds [3] that both males and females are equally employable. Thus, gender cannot be a factor of employability. It does not matter if graduates are male or female. Employability might be influenced by other factors, except for gender. Based on the United Nations Development Programme's gender equality index, the Philippine Commission on Women [20] indicated two-year data. The country sustained its rank (14th) in economic participation and opportunity, while it plunged its rank in educational attainment from the 1 st to the 37 th. With the overall rank in 2019 (ranked 8th), the 2020 performance indicates a decline (ranked 16th).

Napallaton et al., [17] reported that more females are employed in private and public agencies than males. Employability among IT graduates was predominant among single and young females [13]. It was inferred that "employment and underemployment of youth generally appeared to be dichotomous and is largely a function of gender. Gender typecasting is ubiquitous, especially in rural areas. While more males are working, more females are housebound and likely [care] children" [10].

Table-9: T-Test for Independent Results Comparing Employability Using Gender Across Batches of BSE Graduates

\begin{tabular}{|c|c|c|c|c|c|c|c|c|}
\hline Batch & Gender & N & Mean & SD & SE & df & t & sig \\
\hline 2018 & Male & 20 & 2.75 & 3.63 & .74272 & 91 & -.823 & .413 \\
\cline { 2 - 7 } & Female & 69 & 3.65 & 4.91 & .59151 & & & \\
\hline \multirow{2}{*}{2017} & Male & 19 & 9.68 & 6.04 & 1.38719 & 85 & .197 & .844 \\
\cline { 2 - 7 } & Female & 68 & 9.27 & 8.33 & 1.01006 & & & \\
\hline \multirow{2}{*}{2016} & Male & 29 & 13.65 & 10.40 & 1.93189 & 100 & -.531 & .597 \\
\cline { 2 - 6 } & Female & 73 & 14.87 & 10.51 & 1.23124 & & & \\
\hline
\end{tabular}

\section{CONCLUSION}

This tracer study concluded that many of the 2018 BSE graduates were employable to nonpermanent positions compared to the 2017 and 2016 graduates. These individuals were employed within the first six months after graduation. Moreover, there were more 2017 graduates highly employable to permanent positions than those who graduated in 2018 and 2016. This is true within the period between 7 and 12 months after graduation. It was also noticed that there was a trend in the number of graduates who were employable to permanent positions within the thirteen months or so.

As for the curricular program, many of the 2018 Social Studies graduates were employed in the first six months after graduation, while there were many of the 2018 Biological Science graduates employed in the first twelve months. For the 2017 batch, many of the Math graduates were employed in the first six months, and a great number of the Biological Science graduates were employed within 7 to 12 months after graduation. For the 2016 batch, most of the Biological Science graduates were employed in the first six months and a greater proportion of graduates from other programs were employed within 13 months or so.

Regarding employment status, most of 2018, 2017, and 2016 BSE graduates had jobs relevant to their education and training. Experience would matter in obtaining a permanent job. This is true since many of the 2016 graduates had permanent jobs compared to the later batches. By practice and based on policy, DepEd hires applicants who have prior teaching experience and license. The 2016 graduates had been exposed to the labor market for three years now, while the 2017 and
2018 graduates had only been exposed to the labor market for two years or one year, respectively.

Looking at the results, the study implies that the Guidance office may provide more information on hiring and employers relevant to teaching so that right after graduation, graduates can apply and be employed and practice their profession to schools that are not strict to license requirements. The College of Education through relevant offices may provide more training to graduating students relevant to the legalities of employment so that graduates are grounded in policies and regulations as they practice their profession. To do this, the university through the relevant office may establish more linkages that provide continuing education and training to graduating students in preparation for employment.

It is recommended that there would be another tracer study that includes curriculum evaluation in which graduates will look into the knowledge, skills, and values they acquired through years of education at BukSU. They may also assess whether their knowledge, skills, and values were useful or not in their current job. In this way, the university could revisit the curriculum using the information that the graduates can provide in the tracer study.

It is highly suggested that there would be another tracer study that includes employers or direct supervisors of graduates. This is to look into the efficacy of graduates and evaluate whether they are more competitive with other workers in the workplace. 


\section{ACKNOWLEDGEMENT}

We would like to extend our heartfelt gratitude to the faculty of the Professional Studies Department, College of Education, who conducted the tracing of graduates. Without their efforts and outputs, we would not have the data to data-mine. We thank also the administration for allowing the researchers to use the data for this publication.

\section{REFERENCES}

1. Melink, M. \& Pavlin, S. (2009). Employability of graduates and higher education management systems. Slovenia: DEHEMS. https://bit.ly/2Xa7beh

2. Department of Education. (2017). DepEd Order No. 42, s. 2017: Adoption and Implementation of Philippine Professional Standards for Teachers. DepEd. https://bit.ly/32Ymg3w

3. Aspiring Minds. (2016). National Employability Report- Engineers: Annual Report 2016. Aspiring Minds. http://bit.ly/30yD66t

4. Domingo, D. D. (2013). MMSU Graduates' Employability Status and Potentials. MMSU Science and Technology Journal, 3(2), 34-54. http://bit.ly/2L2x4aF

5. Gedye, S., \& Beaumont, E. (2018). The ability to get a job: student understandings and definitions of employability. Education \& Training, 10(5), 406420. http://bit.ly/2XrzrFH

6. Baking, E. G. (2015). Employability and productivity of graduates: An exploratory analysis of program strengths and weaknesses. Journal of Economic Research, 1(1),1-10. http://bit.ly/30cZwtP

7. Smith, C., Ferns, S., \& Russell, L. (2014). The impact of work-integrated learning on student readiness. Final Report. Office for Learning and Teaching, Australia.

8. Finch, D. J., Peacock, M., Levallet, N., Foster, W. (2016). A dynamic capabilities view of employability. Education \& Training, 58(1), 6181. http://bit.ly/2S0Hvfx DOI:10.1108/ET-022015-0013.

9. Philippine Statistical Authority. (2015). Annual Labor and Employment Status (Preliminary results of the 2015 annual estimates). Philippines: Philippine Statistical Authority. http://bit.ly/32lid0u

10. International Labor Organization. (2009). Youth Employability Surveys in the Philippines: An Integrative Report. ILO. https://bit.ly/2xTqptS
11. Infante, J. G., Junco, E. P., \& Marquez, M. C. (2014). Employment Status of the Graduates of Guimaras State College, Philippines. IAMURE International Journal of Multidisciplinary Research, 11. https://bit.ly/32ZFXb6

12. Woya, A. A. (2019). Employability among Statistics Graduates: Graduates' Attributes, Competence, and Quality of Education. Education Research International, 1-7. https://bit.ly/2XhGCnD

13. Javier, B. S. (2015). Determinants of Employability of the Information Technology Graduates in Cagayan State University, Philippines. The Countryside Development Research Journal, 3(1), 43-52. https://bit.ly/2xSmmy2

14. Boholano, H. B. (2012). Employability of Teacher Education Graduates of an Asian Public University. JPAIR Multidisciplinary Research Journal, 9(1), 106-122. https://bit.ly/3bWi1ZB

15. Navida, G. S. (2017). Employability of the Bachelor of Secondary Education Graduates of Pangasinan State University Alaminos City Campus. Journal of Education, Management and Social Sciences, 2(1), 1-6. https://bit.ly/2Xbzadp

16. Abarro, J. O. (2017). Employability of BSE and BEE Graduate of University of Rizal System, Antipolo City. International Journal of Advanced Research, 5(12),1499-1504.

17. Napallaton, N. M., \& G. E. Baquiller, G. E. (2017). Profile and Employability Performance of Jose Rizal Memorial State University Tampilisan Campus Bachelor of Elementary Education Graduates. JPAIR Institutional Research Journal, 10(1), 45-53.

18. Aquino, A. B., Punongbayan, A. J., Macalaguim, L. P., Bauyon, S. M., Rodriquez, R. A., \& Quizon, G. R. (2015). Teacher Education Graduate Tracer Study from 2010 to 2014 in One State University in Batangas, Philippines. Asia Pacific Journal of Multidisciplinary Research, 3(5), 45-50. https://bit.ly/2Rgv147

19. Cañiares, M. J. F. (2015). Tracing University of San Carlos' Science and Mathematics Education Graduates: How are we in developing teacher professionals? International Journal of Research Studies in Education, 4(2), 69-86. https://bit.ly/39JANSa

Philippine Commission on Women. (2019). Philippines drops 8 places in gender equality, remains top in Asia. PCW. https://bit.ly/3e7Busa. 